\title{
Erratum to: A putative role for $\gamma$-aminobutyric acid (GABA) in vascular development in pine seedlings
}

\author{
Juan Jesús Molina-Rueda • María Belén Pascual • \\ José Pissarra $\cdot$ Fernando Gallardo
}

Published online: 15 October 2014

(c) Springer-Verlag Berlin Heidelberg 2014

\section{Erratum to: Planta}

\section{DOI 10.1007/s00425-014-2157-4}

Regrettably, part of the grant detail was omitted in the version of the Acknowledgments officially published. The missing grant numbers have now been included and the correct first line should read:

Acknowledgments This work was supported by Grants from the Spanish Government BIO2003-04590, BIO200606216, P05-AGR-663 and AGL2009-011404.

The online version of the original article can be found under doi:10.1007/s00425-014-2157-4.

J. J. Molina-Rueda · M. B. Pascual · F. Gallardo ( $₫)$

Departamento de Biología Molecular y Bioquímica, Facultad de

Ciencias, Campus de Teatinos, Universidad de Málaga,

29071 Málaga, Spain

e-mail: fgallardo@uma.es

\section{J. J. Molina-Rueda $\cdot$ J. Pissarra}

Departamento de Biologia, Faculdade de Ciências, Universidade do Porto, Rua do Campo Alegre, s/n, 4169-007 Porto, Portugal 